Check for updates

Cite this: RSC Adv., 2018, 8, 21754

Received 11th May 2018

Accepted 6th June 2018

DOI: $10.1039 / c 8 r a 04035 d$

rsc.li/rsc-advances

\title{
Expanding the synthesizable multisubstituted benzo[b]thiophenes via 6,7-thienobenzynes generated from 0 -silylaryl triflate-type precursors $\uparrow$
}

\author{
Suguru Yoshida, (DD *a Tomoko Kuribara, ${ }^{a}$ Takamoto Morita, ${ }^{a}$ Tsubasa Matsuzawa, ${ }^{a}$ \\ Kazushi Morimoto, ${ }^{\text {b }}$ Takuya Kobayashi ${ }^{b}$ and Takamitsu Hosoya (D) *a
}

Various 2,3-disubstituted 6,7-thienobenzynes have been efficiently generated from the corresponding osilylaryl triflate-type precursors by activation with fluoride ions. The method has expanded the scope of synthesizable multisubstituted benzothiophenes, including those with various heteroatom substituents, and can be applied to the synthesis of EP4 antagonist analogs.

\section{Introduction}

Benzo[b]thiophene is one of the structural units frequently found in molecules applied in various research fields, including medicinal chemistry and materials science. ${ }^{1-3}$ Although multisubstituted benzothiophenes are promising compounds as pharmaceutical and organic material candidates, their synthetic approaches are limited. ${ }^{4}$ To improve this situation, we previously reported a facile method to prepare various tetrasubstituted benzothiophenes via thienobenzyne intermediates such as I (Fig. 1A). ${ }^{5}$ Thienobenzynes I were efficiently generated from $o$-iodoaryl triflate-type precursors by treatment with a silylmethyl Grignard reagent at $-78{ }^{\circ} \mathrm{C}$, rendering a diverse range of tetrasubstituted benzothiophenes easily available. ${ }^{6} \mathrm{We}$ considered that the use of $o$-silylaryl triflate-type thienobenzyne precursors would further expand the scope of the synthesizable benzothiophenes (Fig. 1B). This is because generation of arynes from this type of precursor has been generally achieved under mild conditions using a basic activator such as the fluoride ion. $^{7-9}$ Indeed, a wide range of aromatic compounds have become easily available via the transformation of arynes generated from $o$-silylaryl triflate-type precursors. Herein, we report the synthesis of $o$-silylaryl triflate-type 6,7-thienobenzyne precursors, the generation of aryne species from these precursors, and the application of the method to the synthesis of various benzothiophenes including potent analogs of a prostaglandin E receptor subtype 4 (EP4) antagonist.

${ }^{a}$ Laboratory of Chemical Bioscience, Institute of Biomaterials and Bioengineering, Tokyo Medical and Dental University (TMDU), 2-3-10 Kanda-Surugadai, Chiyoda-ku, Tokyo 101-0062, Japan.E-mail: s-yoshida@tmd.ac.jp; thosoya.cb@tmd. ac.jp

${ }^{b}$ Department of Medical Chemistry and Cell Biology, Graduate School of Medicine, Kyoto University, Konoe-cho, Yoshida, Sakyo-ku, Kyoto 606-8501, Japan

$\dagger$ Electronic supplementary information (ESI) available: Experimental procedures, characterization for new compounds including NMR spectra. See DOI: 10.1039/c8ra04035d

\section{Results and discussion}

\section{Synthesis of thienobenzyne precursors}

Similar to our previous synthesis of $o$-iodoaryl triflate-type 6,7thienobenzyne precursors, $o$-silylaryl triflate-type precursors $\mathbf{2 a -}$ d were successfully prepared from the corresponding 2,3disubstituted 6-hydroxybenzo[ $b]$ thiophenes 1a-d (Schemes 1 and 2). ${ }^{5}$ Benzothiophenes $2 \mathbf{a}$-c were prepared from 6-hydroxybenzothiophenes 1a-c according to the facile synthetic method for $o$-silylaryl triflates from phenols as reported by Garg and coworkers; carbamate formation using isopropyl isocyanate, regioselective $C$-silylation via ortho-lithiation, removal of the directing group, and triflylation (Scheme 1). ${ }^{\mathbf{1 0}}$ Although preparation of benzothiophene $\mathbf{2 d}$, bearing a chloro and an amide group, from phenol 1d by the same method was unsuccessful at the step of $C$-silylation via ortho-lithiation, the $C$ -

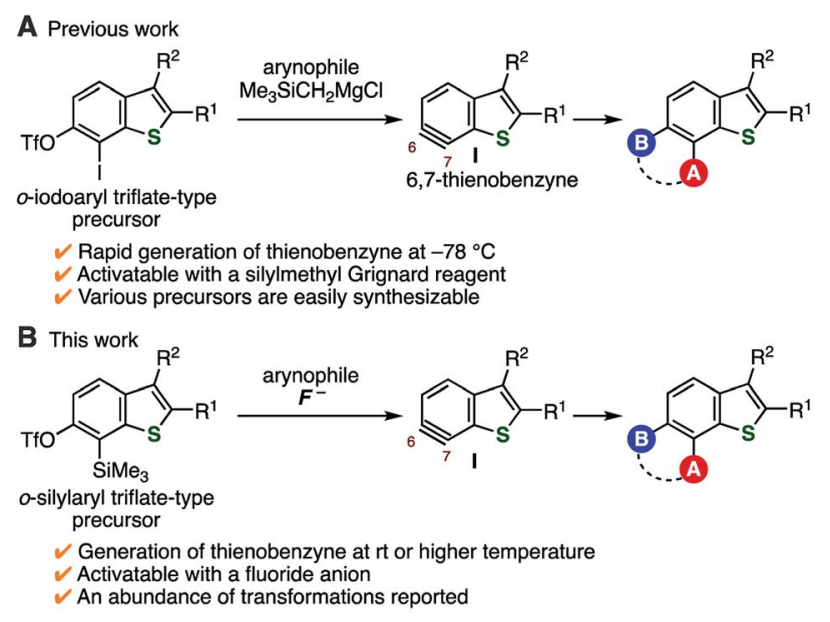

Fig. 1 Transformations via thienobenzyne intermediates I. (A) Our previous work using o-iodoaryl triflate-type precursors. (B) This work using o-silylaryl triflate-type precursors. 


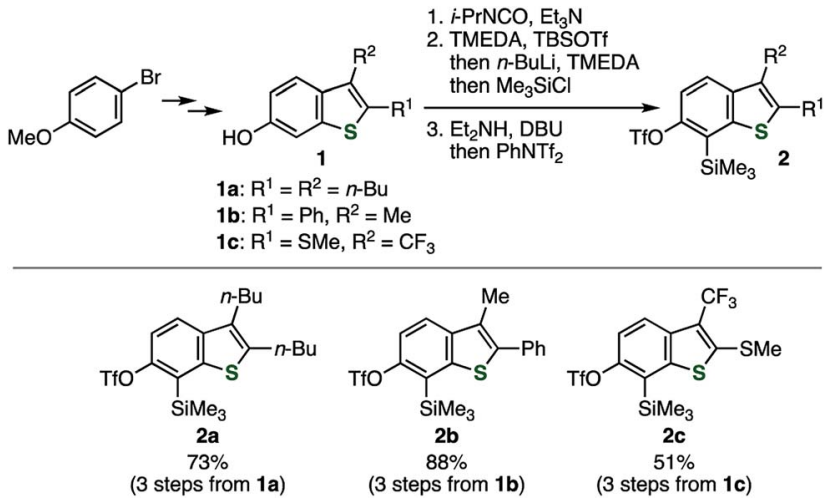

Scheme 1 Synthesis of thienobenzyne precursors $2 a-c$. See the ESI $\uparrow$ for details.
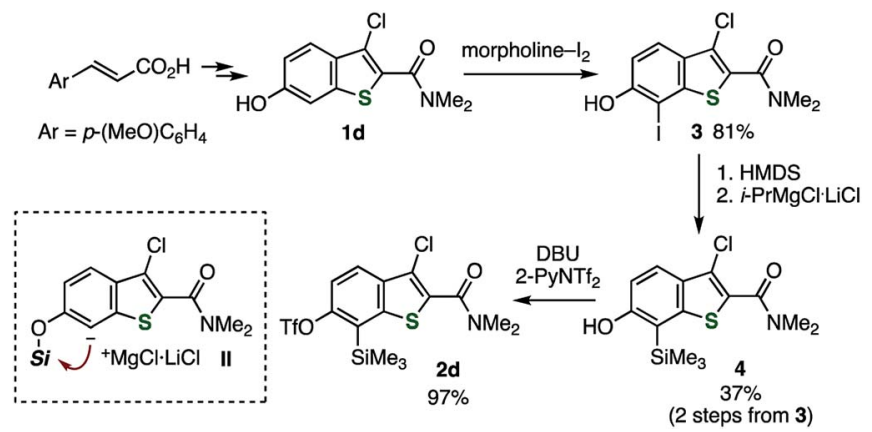

Scheme 2 Synthesis of thienobenzyne precursor $2 \mathrm{~d}$. See the ESI $\dagger$ for details.

silylated product was obtained by an alternative method (Scheme 2). ${ }^{11}$ Thus, regioselective iodination of phenol $\mathbf{1 d}$ with a morpholine-iodine complex, followed by $O$-silylation and treatment with the turbo Grignard reagent to promote the iodine-magnesium exchange reaction and subsequent retroBrook rearrangement via the anionic intermediate II, afforded $o$-silylphenol 4, leaving the chloro and amide groups untouched. Finally, triflylation of $\mathbf{4}$ afforded the desired $\mathbf{2 d} .^{12,13}$ Performing the retro-Brook rearrangement and subsequent $O$ triflylation in one-pot procedure ${ }^{12 a}$ afforded $2 \mathbf{d}$ in $13 \%$ yield.

\section{Optimization of the reaction conditions for generation of thienobenzynes}

The efficient conditions for generating 6,7-thienobenzyne were screened for the reaction between precursor $2 \mathbf{a}$ and azide $5 \mathbf{a}$ in tetrahydrofuran (THF) at room temperature, which revealed that various fluoride sources or cesium carbonate with 18crown-6 were effective as an activator (Table 1). For example, the activation of $2 \mathrm{a}$ with potassium fluoride in the presence of 18crown-6 afforded the desired cycloadduct $\mathbf{6 a}$ with a small amount of regioisomer $\mathbf{6 a}^{\prime}$ (entry 1). The regioselectivity was slightly lower than that observed in the reaction using $o$ iodoaryl triflate-type 6,7-thienobenzyne precursor probably because the reaction triggered by silicate formation was conducted at a higher temperature. Tetra(n-butyl)ammonium
Table 1 Optimization of the reaction conditions

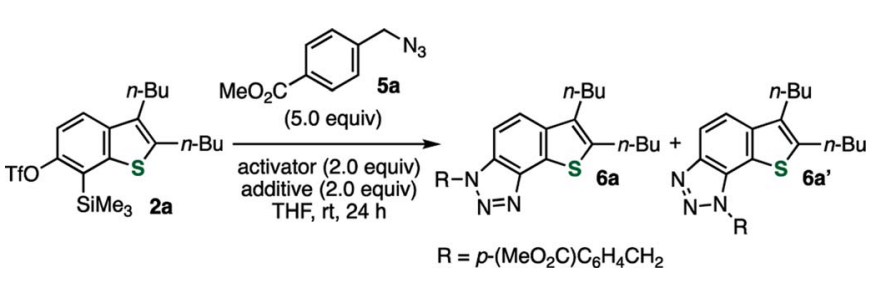

\begin{tabular}{llll}
\hline Entry & Activator & Additive & Yield $^{a}(\%)$ \\
\hline 1 & $\mathrm{KF}$ & 18 -Crown-6 & $78(89: 11)$ \\
2 & $n-\mathrm{Bu}_{4} \mathrm{~N}\left[\mathrm{Ph}_{3} \mathrm{SiF}_{2}\right]$ & - & $73(90: 10)^{b}$ \\
$3^{c}$ & $n-\mathrm{Bu}_{4} \mathrm{NF}$ & - & $69(91: 9)$ \\
4 & $\mathrm{KF}$ & - & 0 \\
5 & $\mathrm{CsF}$ & - & $84(90: 10)^{b}$ \\
$6^{d}$ & $\mathrm{CsF}$ & - & $74(89: 11)$ \\
7 & $\mathrm{Cs}_{2} \mathrm{CO}_{3}$ & 18 -Crown-6 & $75(89: 11)$
\end{tabular}

${ }^{a}$ Yields were determined by ${ }^{1} \mathrm{H}$ NMR analysis, unless otherwise noted.

${ }^{b}$ Isolated yield. ${ }^{c}$ Reaction was performed at $0{ }^{\circ} \mathrm{C} .{ }^{d}$ Azide 5 a (2.0 equiv.) was used.

difluoro(triphenyl)silicate and tetra( $n$-butyl)ammonium fluoride also served as good activators without any additives (entries 2 and 3). While using potassium fluoride alone was ineffective (entry 4), 2a was efficiently activated with cesium fluoride, resulting in the highest combined yield of cycloadducts $\mathbf{6 a}$ and $\mathbf{6 a}^{\prime}$ (entry 5). Considering that the generation of benzyne from $o$ (trimethylsilyl)phenyl triflate with cesium fluoride in THF was reported as inefficient, ${ }^{9 a}$ this result suggests that thienobenzyne precursor 2a is more easily activatable than the simple $o$-silylphenyl triflate. Decreasing the amount of azide 5a to 2.0 equiv. slightly lowered the yield of $\mathbf{6 a} / \mathbf{6} \mathbf{a}^{\prime}$ (entry 6 ). In addition, 6,7thienobenzyne was also generated efficiently under fluoride-free conditions using cesium carbonate and 18-crown-6 (entry 7). ${ }^{9 a}$

\section{Synthesis of various multisubstituted benzothiophenes via thienobenzynes}

Under the optimal conditions, various arynophiles reacted efficiently with thienobenzyne generated from 2a to afford multisubstituted benzothiophenes in high yields (Fig. 2). These include cycloadducts $7, \mathbf{8}, \mathbf{9} / \mathbf{9}^{\prime}$, and $\mathbf{1 0}$ obtained from the reactions with 2,5-dimethylfuran, $N$-phenylpyrrole, $N$-(tert-butyl)- $\alpha$ phenylnitrone, and 1,1-dimethoxyethylene, respectively. The nucleophilic addition of morpholine to the 6,7-thienobenzyne also took place, affording 6-morpholinobenzothiophene $\mathbf{1 1}$ as the major product. The regioselectivity observed using unsymmetrical arynophiles and the nucleophile showed similar trends to their reactions with the same thienobenzyne species generated from the $o$-iodoaryl triflate-type precursor. ${ }^{5}$

An abundance of utilizable transformations is a great advantage of using $o$-silylaryl triflates as aryne precursors over the other types. Indeed, the utility of $o$-silylaryl triflate-type 6,7thienobenzyne precursor was demonstrated through several unique transformations that we recently developed (Fig. 3). ${ }^{14}$ For example, the Michaelis-Arbuzov-type reaction of the 

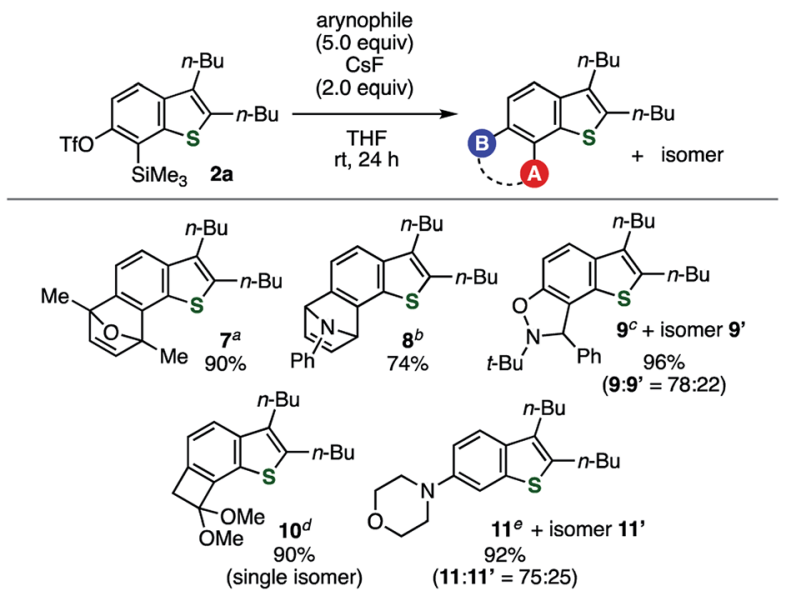

Fig. 2 Reactions of thienobenzyne generated from $2 \mathrm{a}$ with various arynophiles. (a) Reaction with 2,5-dimethylfuran. (b) Reaction with $N$ phenylpyrrole. (c) Reaction with $N$-(tert-butyl)- $\alpha$-phenylnitrone. (d) Reaction with 1,1-dimethoxyethylene. (e) Reaction with morpholine.

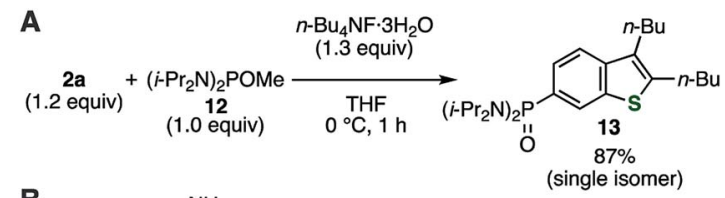

B

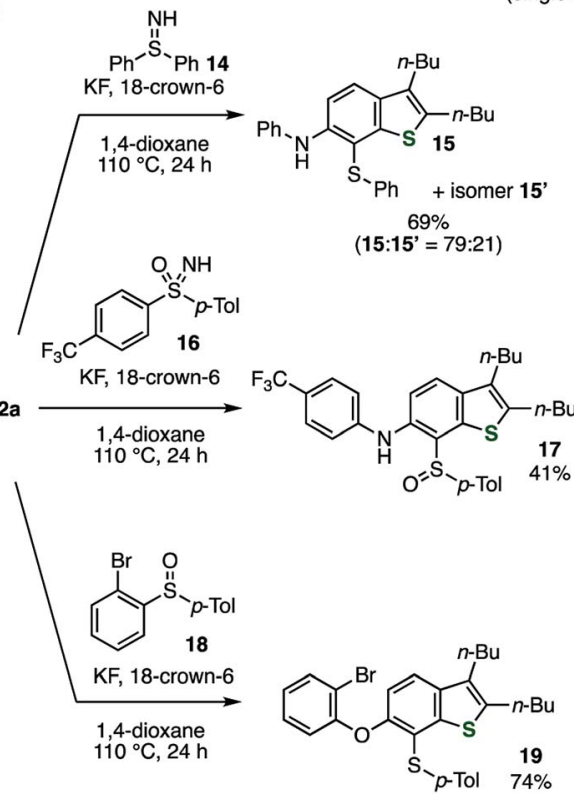

Fig. 3 Transformations via thienobenzyne generated from $2 a$, involving $\mathrm{C}-\mathrm{P}, \mathrm{C}-\mathrm{S}, \mathrm{C}-\mathrm{N}$, and $\mathrm{C}-\mathrm{O}$ bond formations. (A) Reaction with alkoxyphosphine 12. (B) Reactions with sulfilimine 14, sulfoximine 16 , and sulfoxide 18. See the ESI† for details.

thienobenzyne generated from 2a with alkoxyphosphine $\mathbf{1 2}$ proceeded smoothly, affording a high yield of arylphosphonic diamide 13 as the sole product (Fig. 3A). ${ }^{14 a}$ Furthermore, difunctionalizations of the thienobenzyne intermediate with sulfilimine $14,{ }^{14 b}$ sulfoximine $16,{ }^{14 c}$ and sulfoxide $18^{14 d}$ resulted in the selective formation of thioaminated or oxythiolated benzothiophenes $\mathbf{1 5} / \mathbf{1 5}, \mathbf{1 7}$, and $\mathbf{1 9}$, respectively, which are
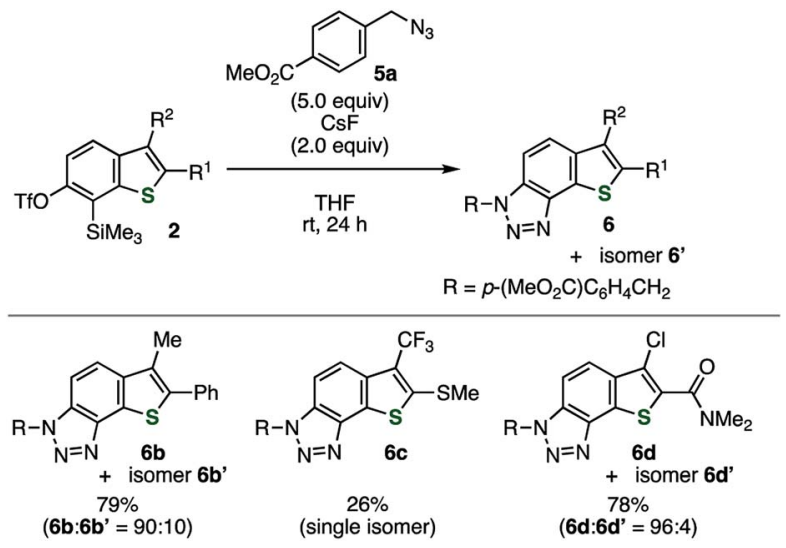

Fig. 4 Cycloadditions of various thienobenzynes generated from precursors $2 b-d$ with azide $5 a$.

difficult to prepare by conventional methods (Fig. 3B). The yields of thioaminated products $\mathbf{1 5} / \mathbf{1 5}^{\prime}$ and $\mathbf{1 7}$ were improved under modified conditions wherein the reactions were carried out at a higher temperature in 1,4-dioxane.

Various 2,3-disubstituted 6,7-thienobenzynes were also generated from precursors $\mathbf{2 b - d}$ (Fig. 4). The reactions of these thienobenzynes with azide 5a afforded triazole-fused 3-methyl2-phenyl-, 2-methylsulfanyl-3-trifluoromethyl-, and 3-chloro-2(dimethylamino)carbonylbenzothiophene derivatives $\mathbf{6 b} / \mathbf{6} \mathbf{b}^{\prime}$, $\mathbf{6 c}$, and $\mathbf{6 d} / \mathbf{6} \mathbf{d}^{\prime}$, respectively, in a regioselective manner. Cycloadduct $\mathbf{6 c}$ was obtained as a single isomer along with complex mixtures of side-products probably due to the effect of the electron-withdrawing trifluoromethyl group. A similar trend was observed in our previous study, ${ }^{5}$ wherein $\mathbf{6 c}$ was obtained without formation of the regioisomer using $o$-iodoaryl triflatetype aryne precursor activated with a silylmethyl Grignard reagent.

\section{Synthesis of the analogs of an EP4 antagonist}

The utility of this method was demonstrated in the facile diversification of the benzo-moiety of the EP4 antagonist 20a developed by Li and coworkers (Scheme 3 ) ${ }^{15}$ The analogs $20 \mathbf{b}-$ d with methyltriazole-fused, benzo-fused, or morpholinosubstituted benzothiophene structure, respectively, were easily prepared via the reactions of the thienobenzyne intermediate generated from 2d with (trimethylsilyl)methyl azide, furan, and morpholine, affording adducts $21 \mathbf{a}-\mathbf{c}$ as the major products. According to the modified method reported previously for the derivatization of 21a to 20b, ${ }^{5}$ EP4 antagonist analogs 20c and 20d were prepared by the Suzuki-Miyaura cross-coupling, the Mitsunobu-type $\mathrm{C}-\mathrm{N}$ bond formation followed by treatment with hydrazine, and amidation. Evaluations of the EP4 receptor binding affinities showed that benzo-fused analog $20 \mathrm{c}\left(K_{\mathrm{i}}=0.18\right.$ $\mu \mathrm{M})$ is a potent EP4 antagonist comparable to the original compound 20a $\left(K_{\mathrm{i}}=0.25 \mu \mathrm{M}\right)$, while methyltriazole-fused analog 20b $\left(K_{\mathrm{i}}=0.47 \mu \mathrm{M}\right)$ and morpholino-substituted analog $\operatorname{20d}\left(K_{\mathrm{i}}=0.70 \mu \mathrm{M}\right)$ are slightly weaker antagonists than $20 \mathrm{a} .{ }^{16}$ This result suggests a possibility for developing more potent EP4 antagonists by further modification of the benzo-moiety of 20a. 


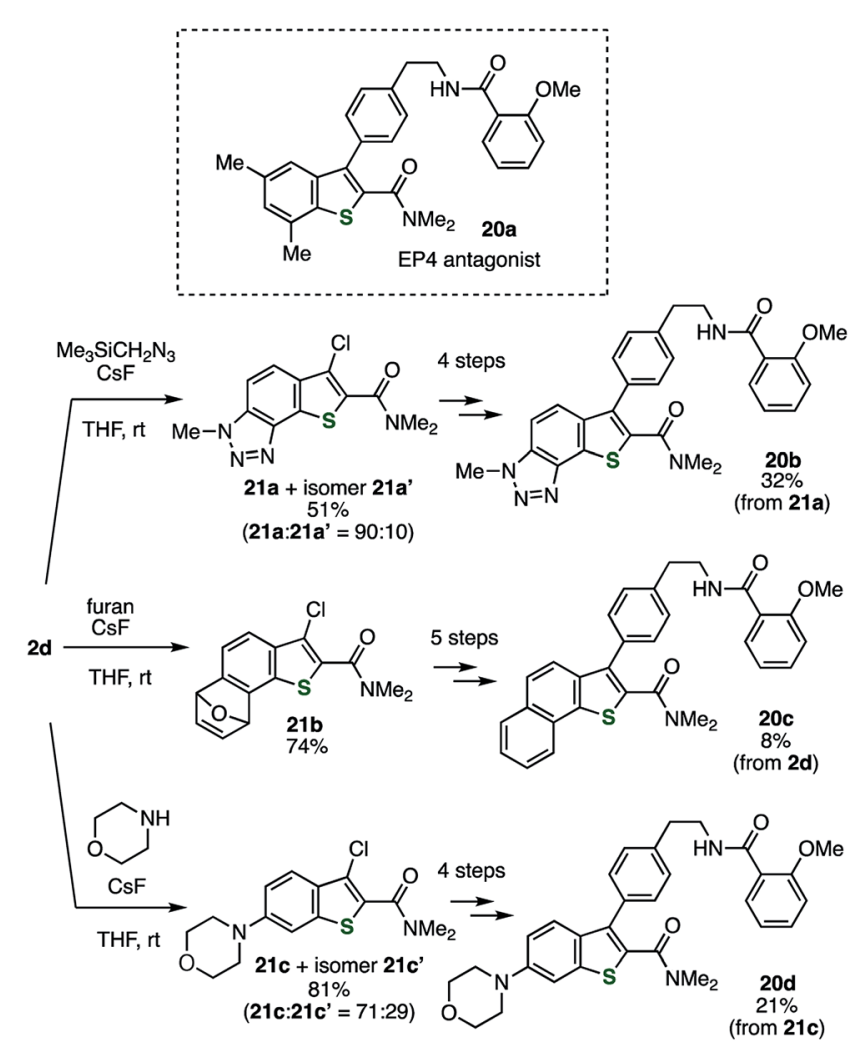

Scheme 3 Synthesis of the analogs of EP4 antagonist 20a. See the $\mathrm{ESI} \uparrow$ for details.

\section{Conclusions}

This study showed that 7-silyl-6-triflyloxybenzo[ $[b]$ thiophenes served as useful precursors of 6,7-thienobenzynes, thus expanding the range of synthesizable multisubstituted benzothiophenes. The utility of the method was demonstrated for the synthesis of various heteroatom-substituted benzothiophenes and the facile structural diversification of an EP4 antagonist that resulted in identification of a potent analog.

\section{Conflicts of interest}

There are no conflicts to declare.

\section{Acknowledgements}

This work was supported by AMED under Grant Numbers JP18am0101098 (Platform Project for Supporting Drug Discovery and Life Science Research (BINDS)) and JP18gm0910007 (CREST; T. Kobayashi and T. H); JSPS KAKENHI Grant Numbers $15 \mathrm{H} 03118$ and $18 \mathrm{H} 02104$ (B; T. H.), $16 \mathrm{H} 01133$ and 18H04386 (Middle Molecular Strategy; T. H.), and 26350971 (C; S. Y.); Suntory Foundation for Life Sciences (S. Y.); Naito Foundation (S. Y.); and the Cooperative Research Project of Research Center for Biomedical Engineering.

\section{Notes and references}

1 (a) K. Koike, Z. Jia, T. Nikaido, Y. Liu, Y. Zhao and D. Guo, Org. Lett., 1999, 1, 197-198; (b) R. S. Keri, K. Chand, S. Budagumpi, S. B. Somappa, S. A. Patil and B. M. Nagaraja, Eur. J. Med. Chem., 2017, 138, 1002-1033.

2 For our study on bioactive benzo[b]thiophenes, see: S. Shimizu, T. Hosoya, M. Murohashi and S. Yoshida, WO 2013/118842, 2013.

3 (a) M. Irie, Chem. Rev., 2000, 100, 1685-1716; (b) T. Yamamoto and K. Takimiya, J. Am. Chem. Soc., 2007, 129, 2224-2225.

4 For selected reports on the synthesis of benzo $[b]$ thiophenes, see: (a) B. L. Flynn, P. Verdier-Pinard and E. Hamel, Org. Lett., 2001, 3, 651-654; (b) I. Nakamura, T. Sato and Y. Yamamoto, Angew. Chem., Int. Ed., 2006, 45, 4473-4475; (c) S. Yoshida, H. Yorimitsu and K. Oshima, Org. Lett., 2007, 9, 5573-5576; (d) C. S. Bryan, J. A. Braunger and M. Lautens, Angew. Chem., Int. Ed., 2009, 48, 7064-7068; (e) L.-L. Sun, C.-L. Deng, R.-Y. Tang and X.-G. Zhang, J. Org. Chem., 2011, 76, 7546-7550; $(f)$ T. Kunz and P. Knochel, Angew. Chem., Int. Ed., 2012, 51, 1958-1961; (g) T. Mori, T. Nishimura, T. Yamamoto, I. Doi, E. Miyazaki, I. Osaka and K. Takimiya, J. Am. Chem. Soc., 2013, 135, 13900-13913; (h) B. Wu and N. Yoshikai, Angew. Chem., Int. Ed., 2013, 52, 10496-10499.

5 T. Morita, S. Yoshida, M. Kondo, T. Matsushita and T. Hosoya, Chem. Lett., 2017, 46, 81-84.

6 For our studies on generation of various arynes from $o$ iodoaryl triflates with a silylmethyl Grignard reagent, see: (a) S. Yoshida, T. Nonaka, T. Morita and T. Hosoya, Org. Biomol. Chem., 2014, 12, 7489-7493; (b) S. Yoshida, K. Uchida, K. Igawa, K. Tomooka and T. Hosoya, Chem. Commun., 2014, 50, 15059-15062; (c) S. Yoshida, K. Uchida and T. Hosoya, Chem. Lett., 2015, 44, 691-693; (d) S. Yoshida, T. Morita and T. Hosoya, Chem. Lett., 2016, 45, 726-728; (e) K. Uchida, S. Yoshida and T. Hosoya, Synthesis, 2016, 48, 4099-4109; (f) S. Yoshida, T. Yano, Y. Nishiyama, Y. Misawa, M. Kondo, T. Matsushita, K. Igawa, K. Tomooka and T. Hosoya, Chem. Commun., 2016, 52, 11199-11202; (g) S. Yoshida, Y. Nakamura, K. Uchida, Y. Hazama and T. Hosoya, Org. Lett., 2016, 18, 6212-6215; (h) T. Morita, Y. Nishiyama, S. Yoshida and T. Hosoya, Chem. Lett., 2017, 46, 118-121; (i) S. Yoshida, A. Nagai, K. Uchida and T. Hosoya, Chem. Lett., 2017, 46, 733-736; (j) S. Yoshida, K. Shimizu, K. Uchida, Y. Hazama, K. Igawa, K. Tomooka and T. Hosoya, Chem.-Eur. J., 2017, 23, 15332-15335.

7 Y. Himeshima, T. Sonoda and H. Kobayashi, Chem. Lett., 1983, 12, 1211-1214.

8 For selected recent reviews on arynes, see: (a) C. M. Gampe and E. M. Carreira, Angew. Chem., Int. Ed., 2012, 51, 37663778; (b) P. M. Tadross and B. M. Stoltz, Chem. Rev., 2012, 112, 3550-3577; (c) H. Yoshida and K. Takaki, Heterocycles, 2012, 85, 1333-1349; (d) H. Miyabe, Molecules, 2015, 20, 12558-12575; (e) S. Yoshida and T. Hosoya, Chem. Lett., 
2015, 44, 1450-1460; (f) J.-A. García-López and M. F. Greaney, Chem. Soc. Rev., 2016, 45, 6766-6798; (g) J. Shi, Y. Li and Y. Li, Chem. Soc. Rev., 2017, 46, 1707-1719; $(h)$ T. Roy and A. T. Biju, Chem. Commun., 2018, 54, 2580-2594.

9 For selected recent reports on arynes generated from $o$ silylaryl triflates, see: (a) S. Yoshida, Y. Hazama, Y. Sumida, T. Yano and T. Hosoya, Molecules, 2015, 20, 10131-10140; (b) S. S. Bhojgude, D. R. Baviskar, R. G. Gonnade and A. T. Biju, Org. Lett., 2015, 17, 6270-6273; (c) J. Shi, D. Qiu, J. Wang, H. Xu and Y. Li, J. Am. Chem. Soc., 2015, 137, 5670-5673; (d) M. Pawliczek, L. K. B. Garve and D. B. Werz, Org. Lett., 2015, 17, 1716-1719; (e) S. Yoshida, K. Shimomori, T. Nonaka and T. Hosoya, Chem. Lett., 2015, 44, 1324-1326; $(f)$ E. Demory, K. Devaraj, A. Orthaber, P. J. Gates and L. T. Pilarski, Angew. Chem., Int. Ed., 2015, 54, 11765-11769; (g) C. M. Holden, S. M. A. Sohel and M. F. Greaney, Angew. Chem., Int. Ed., 2016, 55, 2450-2453; (h) E. Yoshioka, M. Nishimura, T. Nakazawa, S. Kohtani and H. Miyabe, J. Org. Chem., 2015, 80, 8464-8469; (i) T. Ikawa, S. Masuda, A. Takagi and S. Akai, Chem. Sci., 2016, 7, 5206-5211; (j) Y. Li, D. Qiu, R. Gu, J. Wang, J. Shi and Y. Li, J. Am. Chem. Soc., 2016, 138, 10814-10817; $(k)$ Y. Li, C. Mück-Lichtenfeld and A. Studer, Angew. Chem., Int. Ed., 2016, 55, 14435-14438; (l) X. Li, Y. Sun, X. Huang, L. Zhang, L. Kong and B. Peng, Org. Lett., 2017, 19, 838841; $(\mathrm{m})$ T. Kitamura, K. Gondo and J. Oyamada, J. Am. Chem. Soc., 2017, 139, 8416-8419; (n) J. B. Lin, T. K. Shah, A. E. Goetz, N. K. Garg and K. N. Houk, J. Am. Chem. Soc., 2017, 139, 10447-10455; (o) H. Xu, J. He, J. Shi, L. Tan,
D. Qiu, X. Luo and Y. Li, J. Am. Chem. Soc., 2018, 140, 3555-3559; ( $p$ ) P. Garg and A. Singh, Org. Lett., 2018, 20, 1320-1323; $(q)$ V. G. Pandya and S. B. Mhaske, Org. Lett., 2018, 20, 1483-1486; (r) Y. Sumii, Y. Sugita, E. Tokunaga and N. Shibata, ChemistryOpen, 2018, 7, 204-211; $(s)$ P. Gouthami, L. N. Chavan, R. Chegondi and S. Chandrasekhar, J. Org. Chem., 2018, 83, 3325-3332.

10 S. M. Bronner and N. K. Garg, J. Org. Chem., 2009, 74, 88428843.

11 A complex mixture of products was obtained.

12 For selected reports on the synthesis of $o$-silylaryl triflates via the retro-Brook rearrangement, see: (a) D. Peña, A. Cobas, D. Pérez and E. Guitián, Synthesis, 2002, 1454-1458; (b) D. J. Atkinson, J. Sperry and M. A. Brimble, Synthesis, 2010, 911-913; (c) B. Michel and M. F. Greaney, Org. Lett., 2014, 16, 2684-2687.

13 For a review of the turbo Grignard reagent, see:R. L.-Y. Bao, R. Zhaoa and L. Shi, Chem. Commun., 2015, 51, 6884-6900.

14 (a) S. Yoshida and T. Hosoya, Chem. Lett., 2013, 42, 583-585; (b) S. Yoshida, T. Yano, Y. Misawa, Y. Sugimura, K. Igawa, S. Shimizu, K. Tomooka and T. Hosoya, J. Am. Chem. Soc., 2015, 137, 14071-14074; (c) S. Yoshida, H. Nakajima, K. Uchida, T. Yano, M. Kondo, T. Matsushita and T. Hosoya, Chem. Lett., 2017, 46, 77-80; (d) T. Matsuzawa, K. Uchida, S. Yoshida and T. Hosoya, Org. Lett., 2017, 19, 5521-5524.

15 L. Li, M.-C. Mathieu, D. Denis, A. G. Therien and Z. Wang, Bioorg. Med. Chem. Lett., 2011, 21, 734-737.

16 See the ESI $\dagger$ for details. 